\title{
Stability of gamma-valerolactone under pulping conditions as a basis for process optimization and chemical recovery
}

\author{
Marianna Granatier (D) Inge Schlapp-Hackl • Huy Quang Lê • Kaarlo Nieminen • \\ Leena Pitkänen $\cdot$ Herbert Sixta 1
}

Received: 29 May 2021/Accepted: 30 September 2021 / Published online: 13 October 2021

(C) The Author(s) 2021

\begin{abstract}
This study focuses on the investigation of the extent of the $\gamma$-valerolactone (GVL) hydrolysis forming an equilibrium with 4-hydroxyvaleric acid (4HVA) in aqueous solutions over a wide $\mathrm{pH}$ range. The hydrolysis of a $50 \mathrm{wt} \%$ GVL solution to 4-HVA (3.5 mol\%) was observed only at elevated temperatures. The addition of sulfuric acid $\left(0.2 \times 10^{-5} \mathrm{wt} \%\right.$ to $6 \mathrm{wt} \%)$ at elevated temperatures $\left(150-180{ }^{\circ} \mathrm{C}\right)$ and reaction times between 30 and $180 \mathrm{~min}$ caused the formation of 4 mol\% 4-HVA. However, with decreasing acidity, the 4-HVA remained constant at about $3 \mathrm{~mol} \%$. The hydrolysis reactions in alkaline conditions were conducted at a constant time $(30 \mathrm{~min})$ and temperature $\left(180{ }^{\circ} \mathrm{C}\right)$ with the variation of the $\mathrm{NaOH}$ concentration $\left(0.2 \times 10^{-6} \mathrm{wt} \%\right.$ to $\left.7 \mathrm{wt} \%\right)$. The addition of less than $0.2 \mathrm{wt} \%$ of $\mathrm{NaOH}$ resulted in the formation of less than 4 mol\% of sodium 4-hydroxyvalerate. A maximum amount of $21 \mathrm{~mol} \%$ of 4-HVA was observed in a $7 \mathrm{wt} \% \mathrm{NaOH}$ solution. The degree of decomposition after treatment was determined by NMR analysis. To verify the GVL stability
\end{abstract}

Supplementary Information The online version contains supplementary material available at https://doi.org/10.1007/ s10570-021-04243-5.

M. Granatier · I. Schlapp-Hackl ·

H. Q. Lê · K. Nieminen · L. Pitkänen · H. Sixta ( $ه)$

Department of Biosystems and Bioproducts, School of

Chemical Engineering, Aalto University, Vuorimiehentie

1, 02150 Espoo, Finland

e-mail: herbert.sixta@aalto.fi under practical conditions, Betula pendula sawdust was fractionated in $50 \mathrm{wt} \% \mathrm{GVL}$ with and without the addition of $\mathrm{H}_{2} \mathrm{SO}_{4}$ or $\mathrm{NaOH}$ at $180{ }^{\circ} \mathrm{C}$ and a treatment time of $120 \mathrm{~min}$. The spent liquor was analyzed and a 4-HVA content of $5.6 \mathrm{~mol} \%$ in a high acidic $(20 \mathrm{~kg}$ $\mathrm{H}_{2} \mathrm{SO}_{4} / \mathrm{t}$ wood) and $6.0 \mathrm{~mol} \%$ in an alkaline $(192 \mathrm{~kg}$ $\mathrm{NaOH} / \mathrm{t}$ wood) environment have been determined.

Keywords Biorefineries · Gamma-valerolactone · Organosolv $\cdot$ Pulping

\section{Introduction}

The worldwide economy is currently highly dependent on the use of fossil raw materials. Various drawbacks associated with the exploitation of fossil resources, such as non-renewability, pollution, insecurity, and the massive climate change crisis, have promoted the transition to a more sustainable bioeconomy, centered on lignocellulosic biomass. Lignocellulosic material is an abundant, renewable, and relatively cheap carbonbased material. In detail, cellulose, with its unique properties, represents the most important component of fractionated lignocellulose (Henriksson and Lennholm 2009) and is mainly processed into paper-grade and dissolving-grade pulps via chemical pulping.

The global annual production of chemical pulp is more than 144 Mton (Statista, 2021). Despite the 
constant decline in demand for graphic paper, the paper-grade pulp is still indispensable for the constantly growing need for tissues, hygiene, and packaging products. On contrary, the segment for dissolving pulp forms a fast-growing niche market with an annual production of 10.2 million tons in 2019 (Engelhardt 2020). Dissolving pulp is characterized by a high $\alpha$-cellulose content $(>90 \%)$ and targeted for higher-valued applications such as regenerated cellulose, cellulose esters or ethers, nano- or microcrystalline cellulose.

The majority of dissolving pulp is currently obtained from wood by chemical pulping using acid sulfite (AS) and pre-hydrolysis kraft (PHK) processes. Whereas the new plants are applying the PHK technique almost exclusively (Chen et al. 2016; Schild et al. 2010; Sixta 2006). However, despite a high degree of technical maturity, AS and PHK encounter several drawbacks such as unsatisfactory yields, lignin containing chemically-bonded sulfur, degraded hemicelluloses (PHK), non-reusable cooking ingredients, and alarming environmental concerns (AS) (Gellerstedt 2009; Mendes et al. 2009; Sixta et al. 2013). As a response to these disadvantages, organosolv pulping was introduced (Kleinert and Tayenthal 1931).

Up to now, the capability of many organic lignin solvents (like ethanol, acetone, acetic acid, or formic acid) for the fractionation of biomass has been investigated and various methods have been established. Due to its eco-friendly properties and the capability to separate cellulose, hemicellulose, and lignin, ethanol attracted attention first and has been utilized by the well-investigated ALCELL (ethanol/ water) and SEW (SO2-ethanol-water) techniques. Both have already reached the pilot and the former even demonstration scale, but the recently confirmed loss of ethanol, as a consequence of the formation of covalent linkages with lignin and carbohydrates, poses a major challenge to the commercialization (van Heiningen et al. 2018).

Recently, one of the biomass-originated, green solvents $\gamma$-valerolactone (GVL), which is currently present in a wide range of food and cosmetic products, was introduced by Horváth et al. (2008) as a sustainable liquid for chemical conversion, and proposed by Fang and Sixta (2014) as a solvent for biomass pulping (Fang and Sixta 2014; Horváth et al. 2008). Since then, several research groups tested the capability of GVL for the fractionation of biomass at acid-catalyzed conditions at mild temperatures or of agricultural waste and its transformation to furfural and fermentable sugars (Alonso et al. 2017; Li et al. 2016; Qing et al. 2018; Shuai et al. 2016).

Previously, Lê et al. contributed to the development of the GVL based biorefineries and demonstrated the uncatalyzed fractionation of hardwood in a $50 \mathrm{wt} \%$ GVL aqueous solution at elevated temperatures. Viscose-grade dissolving pulp readily convertible to regenerated fibers for textile applications or nanofibrillated cellulose was successfully separated for the first time (Lê et al. 2018a). Besides, the spent liquor contained extracted wood components, which can be isolated and potentially upgraded to a wide range of biorefinery products such as sulfur-free lignin, xylose, furfural, and carboxylic acids. More than $90 \%$ of the solvent (GVL) can be recovered by liquid $\mathrm{CO}_{2^{-}}$ extraction and optionally in combination with a preceding water-evaporation stage (Fang and Sixta 2014; Lê et al. 2016a, 2018a, b).

Generally, the feasibility of the organosolv method and its market potential relies on many process-related factors like solvent stability, recyclability, price, product yield, safety, or toxicity of the process. GVL demonstrated remarkable properties, but for its use as a solvent in an industrially relevant pulping process, a proper evaluation of its decomposition behavior under pulping conditions has to be performed.

GVL (5-methyloxolan-2-one) is a five-membered lactone and is well-known for its non-toxicity, lowvolatility, high solubility in water $(>100 \mathrm{mg} / \mathrm{ml})$, low melting $\left(-31^{\circ} \mathrm{C}\right)$, and high boiling point $\left(205{ }^{\circ} \mathrm{C}\right)$. It is chemically stable under standard temperature and pressure, resistant to degradation and oxidation, and in combination with water, it forms a zeotropic mixture (Lê et al. 2016b). Despite the high stability at neutral and ambient conditions, the lactone ring of GVL tends to hydrolyze in water, especially in an acidic environment and forms an equilibrium with its hydrolysis product, the 4-hydroxyvaleric acid (4-HVA) (Wong et al. 2017). The hydrolysis in an alkaline environment is more detrimental for the lactone ring due to the irreversible salt formation, the 4-hydroxyvalerate. It is noteworthy that in specific cases, which include high reaction temperatures or prolonged reaction times compared to pulping conditions, GVL undergoes a ring-opening reaction followed by an $\mathrm{H}$-shift to form the corresponding Olefinic acid, the 3-pentenoic acid (Alonso et al. 2017; Luterbacher et al. 2014). 
This work aims at the examination of the key fundamentals for the practical development of a new organosolv process. In comparison to Wong et al. (2017), the GVL/4-HVA equilibrium is investigated more closely with the stress on conditions that are more relevant to the fractionation process. Additionally, to the best of our knowledge, for the very first time, the patterns of equilibrium between GVL and 4-HVA under actual Betula pendula sawdust cooking in the spent liquor are presented.

\section{Experimental}

Material

GVL ( $\geq 99$ wt\% purity, (RS)-Form) and 1,3,5trimethoxybenzen ( $\geq 99 \mathrm{wt} \%$ ) were purchased from Sigma Aldrich, sulfuric acid (95-97.0 wt \%) from Merck, and sodium hydroxide pellets ( $\geq 98 \mathrm{wt} \%$ ) from VWR Chemicals. Besides, the solvents for NMR analysis, dimethyl sulfoxide- $\mathrm{d}_{6}(99.8 \%)$, acetone- $\mathrm{d}_{6}$ $(99.8 \%)$, acetonitrile- $d_{3}(99.8 \%)$ were obtained from Eurisotop and deuterated water- $\mathrm{d}_{2}(99.8 \%)$ from Acros Organics. Betula pendula wood chips were supplied by Stora Enso (Finland). The chips were stored at $-20{ }^{\circ} \mathrm{C}$ and ground by the use of a Wiley mill (Arthur H. Thomas Co., model No. 2, $1 \mathrm{~mm}$ screen opening) before usage. The wood composition was screened according to the SCAN-CM 40:01 standard and the amount of sugars was calculated based on the Janson formula (Janson 1970). For the stability experiments, GVL was distilled to a purity of 99.9 wt\% (analyzed by gas chromatography). The water used in the experiments was purified by a Millipore Synergy ${ }^{\circledR}$ UV system (water resistivity of $18.2 \mathrm{M} \Omega$ ).

Analytical methods

Mixtures have been homogenized by the use of a vortex mixer (Vortex-Genie 2, Scientific Industries, Inc., US) and all thermal treatments have been performed in a microwave reactor (Monowave 300, Anton Paar GmbH, Graz, Austria). The $\mathrm{pH}$ value was determined by a pH meter (Thermo Scientific). The ${ }^{1} \mathrm{H}$ NMR spectra were recorded on a Bruker AV III $400 \mathrm{MHz}$ spectrometer. The spectra were referenced against the ${ }^{1} \mathrm{H}$ peaks of the deuterated solvents and the concentration of the GVL and 4-HVA compounds were determined related to the defined concentration of the standard 1,3,5-trimethoxybenzene ( $\geq 99 \mathrm{wt} \%$ ).

Statistical model

A full factorial design for an experiment having three factors (temperature, time, and $\mathrm{pH}$ ) each with four levels would require 64 runs $(4 \times 4 \times 4)$ for all possible combinations of levels. Selecting a fractional factorial design is a customary method for reducing the number of runs while maintaining an effective cover for most experimental variables of interest. Employing the scheme of connecting the levels of a four-level factor to a pair of two-level factors (the most commonly used) transforms the three-factor all fourlevel full plan (64 runs) to a six-factor all two-level plan (32 runs). Employing the same scheme in the opposite direction transforms the fractional design back to a design with three four-level factors (Table S1).

Thermal reaction of GVL in acidic or alkaline conditions

In total four $\mathrm{H}_{2} \mathrm{SO}_{4}$ and four $\mathrm{NaOH}$ stock solutions have been used. $2 \mathrm{~g}$ of pure GVL $(0.020 \mathrm{~mol})$ are mixed with water and $\mathrm{H}_{2} \mathrm{SO}_{4}$ or $\mathrm{NaOH}$ (stock solutions) in a $10 \mathrm{ml}$ vial (detailed information is given in SI Table S2). The solutions were thoroughly mixed for a few seconds and the $\mathrm{pH}$ value was recorded. The mixtures were thermally treated at temperatures between $150{ }^{\circ} \mathrm{C}$ up to $180{ }^{\circ} \mathrm{C}$ at a constant stirring speed of $600 \mathrm{rpm}$. The reaction time was chosen between 30 and $180 \mathrm{~min}$. After the thermal treatment, the samples were cooled to room temperature and the $\mathrm{pH}$ was measured. The formation of 4-HVA was analyzed by NMR analysis. The NMR samples were prepared by dissolving $0.01 \mathrm{~g}$ of sample and $0.01 \mathrm{~g}$ of the standard 1,3,5-trimethoxybenzene $(0.000059 \mathrm{~mol})$ in $0.5 \mathrm{ml} \mathrm{DMSO}-\mathrm{d}_{6}$ directly in the NMR tube. The amounts of 4-HVA in mol\% and the $\mathrm{pH}$ values before and after treatment are presented in SI (Table S2).

Wood fractionation and spent liquor analysis

Betula pendula (silver birch) wood chips were ovendried at $40{ }^{\circ} \mathrm{C}$ overnight and milled to sawdust. Betula pendula wood comprised of $42.4 \%$ cellulose, $28.0 \%$ 
C5 hemicellulose, $3.6 \%$ C6 hemicellulose, $21.8 \%$ lignin, and $1.7 \%$ extractives. $7.5 \mathrm{~g}$ of pure GVL $(0.075 \mathrm{~mol})$ was mixed with different solutions of $\mathrm{H}_{2} \mathrm{SO}_{4}$ and $\mathrm{NaOH}$ (Table S3). The solutions were thoroughly mixed for a few seconds and the $\mathrm{pH}$ value was recorded. Afterward, $1.5 \mathrm{~g}$ of oven-dried sawdust were added and treated in Anton Paar microwave reactor at $180{ }^{\circ} \mathrm{C}$, for $120 \mathrm{~min}$ (liquor-to-wood ratio of

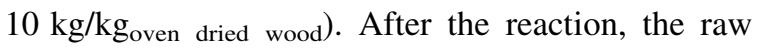
spent liquor was separated from the pulp suspension by filtration and the pulp was washed with $37.5 \mathrm{wt} \%$ aqueous GVL solution $(20 \mathrm{~g}, 5.9 \mathrm{~mol} / \mathrm{L})$. The raw spent liquor and GVL washing filtrate were combined and analyzed by NMR. For NMR measurement, $0.01 \mathrm{~g}$ of spent liquor and $0.01 \mathrm{~g}$ of standard 1,3,5trimethoxybenzene $(0.000059 \mathrm{~mol})$ were dissolved in $0.5 \mathrm{ml}$ DMSO- $\mathrm{d}_{6}$ directly in the NMR vial. The pulp was subjected to a final washing stage with boiling water with a liquor-to-wood ratio of $130 \mathrm{~kg}$ of water/ $\mathrm{kg}$ wood and dried at $105{ }^{\circ} \mathrm{C}$. The amounts of 4-HVA in $\mathrm{mol} \%$ and the $\mathrm{pH}$ values before and after treatment are summarized in Table 1.

Development of an analytical method for quantification of the GVL/4-HVA equilibrium

In analogy to the study of Wong et al. (2017) and due to the great solubility of GVL, 4-HVA as well as 3-pentenoic acid in different solvents, NMR was the chosen tool. All of the compounds show peaks of great intensity and due to the nature of the structures, the signals are well separated and distinguished. One of the prerequisites for the accurate determination of the GVL and 4-HVA equilibria was to choose a suitable solvent for ${ }^{1} \mathrm{H}$ NMR analysis. Thereby, an equal amount of an acidic sample $(0.01 \mathrm{~g})$ of $50 \mathrm{wt} \% \mathrm{GVL}$ combined with $1.8 \mathrm{wt} \% \mathrm{H}_{2} \mathrm{SO}_{4}$ at $180{ }^{\circ} \mathrm{C}$ treated for $30 \mathrm{~min}$ was dissolved in four different solvents (DMSO- $\mathrm{d}_{6}$, acetone- $\mathrm{d}_{6}$, acetonitrile- $\mathrm{d}_{3}$, and $\mathrm{D}_{2} \mathrm{O}$ ) and immediately analyzed. The change of the mixtures was monitored at regular intervals until the equilibria were reached. As expected, the ${ }^{1} \mathrm{H}$ NMR spectra revealed differences in the chemical shifts. Large variations in the 4-HVA concentrations were observed too, which implies that not all solvents showed inert behavior. The 4-HVA concentrations measured in DMSO- $\mathrm{d}_{6}$ and $\mathrm{D}_{2} \mathrm{O}$ were comparable to a sample analyzed without any NMR solvent (ca. $4.3 \mathrm{~mol} \%$ ). In contrast, lower amounts of 4-HVA were formed in acetone- $\mathrm{d}_{6} \quad(0.3 \mathrm{~mol} \%), \quad$ and acetonitrile- $\mathrm{d}_{3}$ (0.1 mol\%) (Fig. 1).

As a result, DMSO- $\mathrm{d}_{6}$ was chosen as the most suitable solvent for ${ }^{1} \mathrm{H}$ NMR analysis due to the highest accuracy of the results, the good dissolution behavior of all components, and the well-defined, nonoverlapping peaks of the $-\mathrm{CH}_{3}$ groups of GVL, 4-HVA, and the standard (1,3,5-TMB) (Fig. 2). The DMSO- $\mathrm{d}_{6}$ peak at $2.5 \mathrm{ppm}$ was always defined as an internal reference peak, and the concentration of GVL and 4-HVA was detected via integration of the peak area (shift at 1.29-1.30 ppm and 1.01-1.04 ppm, respectively) with regard to the standard. In pure GVL, no 4-HVA was recognized at between 1.01 and $1.04 \mathrm{ppm}$. Unlike at basic and acidic conditions a
Table 1 The concentration of 4-HVA in spent liquor after fractionation of Betula pendula in a $50 \mathrm{wt} \% \mathrm{GVL}$ water solution at $180{ }^{\circ} \mathrm{C}$ and $120 \mathrm{~min}$ at acidic or basic conditions

\begin{tabular}{lcclll}
\hline Sample & $\mathrm{kg} \mathrm{H}_{2} \mathrm{SO}_{4} / \mathrm{t}_{\text {wood }}$ & $\mathrm{kg} \mathrm{NaOH} / \mathrm{t}_{\text {wood }}$ & $4-\mathrm{HVA}[\mathrm{mol} \%]$ & $\mathrm{pH}_{\text {initial }}$ & $\mathrm{pH}_{\text {Spent liquor }}$ \\
\hline 1 & 0.000 & 0.000 & 3.96 & 3.97 & 3.35 \\
2 & 0.024 & 0.000 & 4.06 & 3.88 & 3.46 \\
3 & 0.231 & 0.000 & 4.31 & 3.24 & 3.49 \\
4 & 2.232 & 0.000 & 5.25 & 2.36 & 3.11 \\
5 & 3.844 & 0.000 & 3.65 & 1.64 & 2.59 \\
6 & 6.058 & 0.000 & 3.86 & 1.66 & 2.30 \\
7 & 7.541 & 0.000 & 4.41 & 1.38 & 2.06 \\
8 & 10.893 & 0.000 & 4.08 & 1.49 & 1.96 \\
9 & 17.259 & 0.000 & 5.51 & 1.21 & 2.06 \\
10 & 0.000 & $2.009 * 10^{-5}$ & 4.18 & 4.04 & 3.42 \\
11 & 0.000 & 0.019 & 4.12 & 4.21 & 3.40 \\
12 & 0.000 & 1.911 & 3.24 & 6.00 & 3.76 \\
13 & 0.000 & 192.113 & 5.88 & 8.62 & 5.69 \\
\hline
\end{tabular}




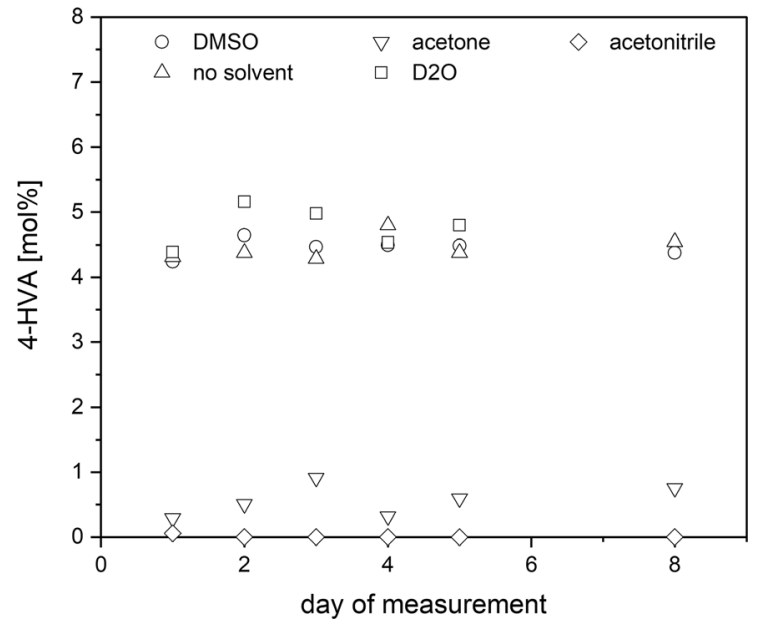

Fig. 1 4-HVA equilibria in DMSO- $\mathrm{d}_{6}$, acetone- $\mathrm{d}_{6}$, acetonitrile$\mathrm{d}_{3}$, and $\mathrm{D}_{2} \mathrm{O}$. Reaction conditions: $50 \mathrm{wt} \% \mathrm{GVL}, \mathrm{pH}=1$, $180{ }^{\circ} \mathrm{C}, 30 \mathrm{~min}, 1.8 \mathrm{wt} \% \mathrm{H}_{2} \mathrm{SO}_{4}$

4-HVA peak was formed (Fig. 2). All spectra with detailed shifts can be found in SI (Figure S2-S15). Furthermore, the visibility of $1 \%$ pentenoic acid was tested resulting in the detection of these small traces with great intensity (Figure S16).

\section{Results and discussion}

Hydrolysis of GVL and formation of 4-HVA as a function of $\mathrm{pH}$ (time and temperature)

$\gamma$-Valerolactone (GVL) belongs to the group of carboxylic acid derivatives. The structure exhibits a cyclic ester, which is formed by an intramolecular reaction of a hydroxycarboxylic acid under the elimination of water (Graham 2004). Due to the relatively large size and high energy barrier, $\gamma$ lactones are stable heterocycles and do not decompose readily in a neutral aqueous solution at ambient conditions. Hydrolysis only appears via a nucleophilic substitution mechanism in both, acid and basic catalyzed solutions. Thereby, a water molecule attacks the electrophilic carbon of the carbonyl group and causes an acyl-oxygen cleavage. At certain conditions, the heterocyclic ring of GVL is thus opened, resulting in the formation of 4-hydroxyvaleric acid (4-HVA) under the establishment of an equilibrium (GómezBombarelli et al. 2013a, b).

Following the conditions proposed by Lê et al. for the fractionation of Eucalyptus globulus sawdust (Lê et al. 2016a), the stability of GVL was firstly determined in a $50 \mathrm{wt} \%$ aqueous solution at $180{ }^{\circ} \mathrm{C}$ in the absence of wood. The importance of heating was

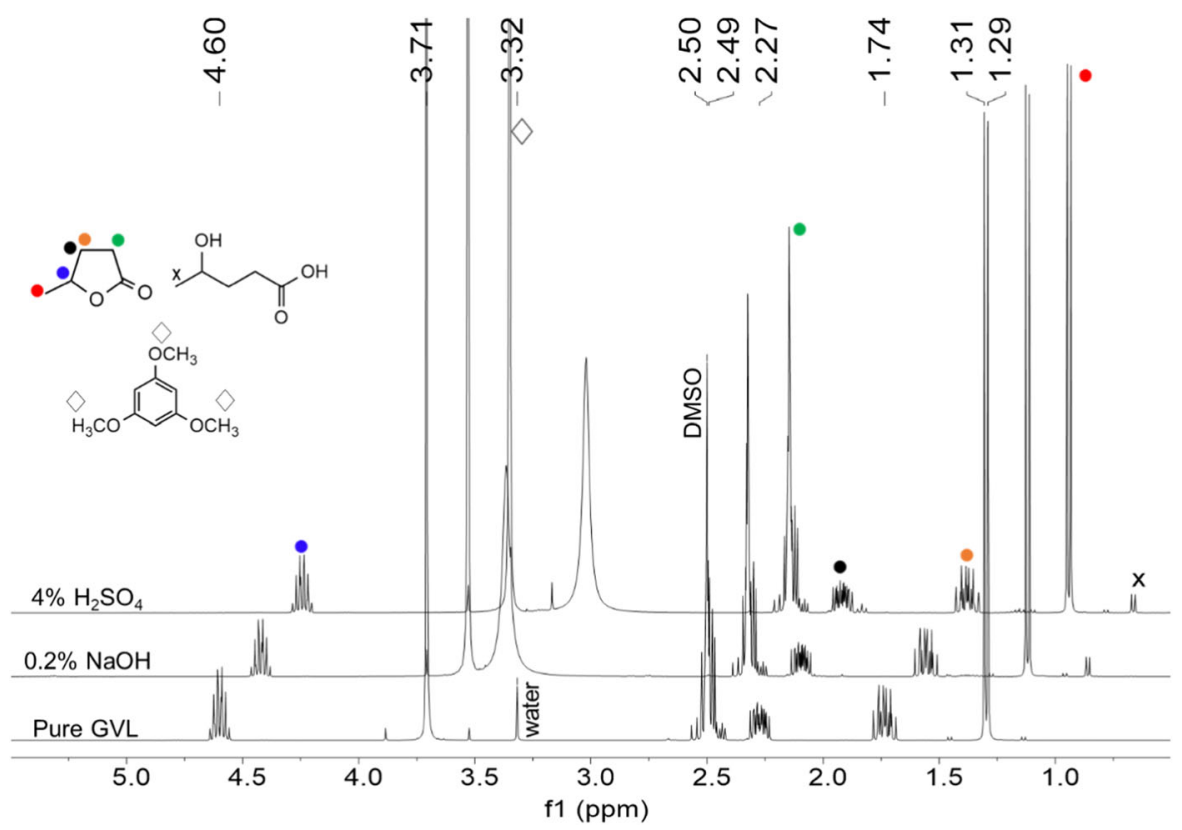

Fig. 2 Comparison of ${ }^{1} \mathrm{H}$ NMR spectra of pure GVL, GVL treated with $\mathrm{H}_{2} \mathrm{SO}_{4}$ and $\mathrm{NaOH}$ 
proven again. Hydrolysis of GVL to 4-HVA was observed only after thermal treatment and the reached equilibrium was determined by repeated re-analysis. The extent of hydrolysis depends on the GVL concentration or, conversely, on the amount of water in the solution. In the case of $50 \mathrm{wt} \% \mathrm{GVL}, 3.4 \mathrm{~mol} \%$ of 4-HVA was obtained. In contrast, in the case of 87 wt\% GVL, no more than 0.8 mol\% 4-HVA was yielded (Table S4). At neutral conditions, water acts as a weak nucleophile and an increase of the acidity enhances the basicity of the water.

An acid catalyst activates the carbonyl group by protonation of the carbonyl oxygen and thus a nucleophilic attack by water is favored (Fig. 3) (Graham 2004). The effect of acidic conditions regarding a $50 \mathrm{wt} \% \mathrm{GVL}$ aqueous solution was traced by a stepwise elevation of the $\mathrm{H}_{2} \mathrm{SO}_{4}$ concentration from $0.2 \times 10^{-5} \mathrm{wt} \%$ to $6 \mathrm{wt} \%$ at elevated temperatures $\left(150-180{ }^{\circ} \mathrm{C}\right)$ at reaction times between 30 and $180 \mathrm{~min}$. The addition of sulfuric acid resulted in the formation of a stable GVL/4-HVA equilibrium. After all, the formation of 4-HVA did not exceed $4 \mathrm{~mol} \%$ and with decreasing acidity to near neutral, the 4-HVA concentration remained constant at about $3 \mathrm{~mol} \%$ (Fig. 4a). The equilibrium stability of the mixtures was determined by NMR analysis at regular intervals. As no changes were detected, equilibrium was reached after the treatment.

The results are consistent with the general theory of acidic ester hydrolysis. The acid-catalyzed mechanism is a reversible reaction resulting from the absence of salt formation. In acidic conditions, the protons of the acid are regenerated (Graham 2004) and thus only a

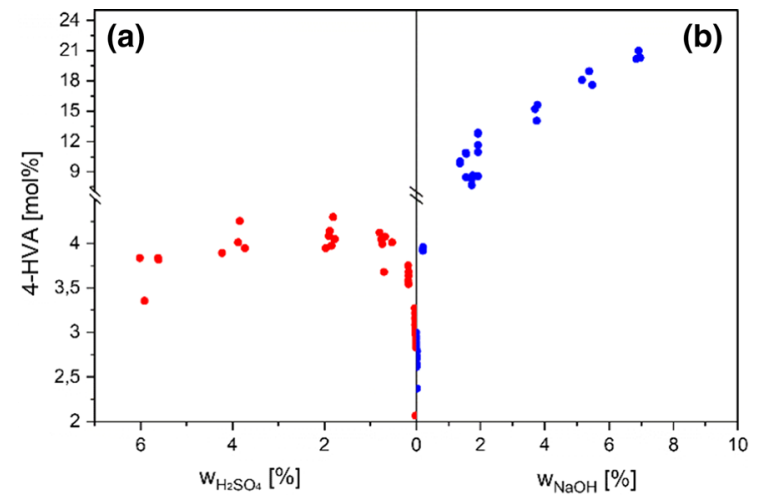

Fig. 4 a Concentration of 4-HVA formed in GVL-water solutions after treatment at $150-180{ }^{\circ} \mathrm{C}$ for $30-180 \mathrm{~min}$ in the presence of $\mathrm{H}_{2} \mathrm{SO}_{4}\left(0.0-6.0 \mathrm{wt} \%\right.$, $\left.\mathrm{pH}_{\text {initial }}=0-6\right)$ b Concentration of 4-hydroxyvalerate formed in GVL-water solution after treatment at $180{ }^{\circ} \mathrm{C}$ for $30 \mathrm{~min}$ in the presence of $\mathrm{NaOH}(0-7$ $\mathrm{wt} \%, \mathrm{pH}_{\text {initial }}=4-9$ )

small amount of acid (0.7 wt \%) is sufficient to reach the maximum concentration of 4-HVA ( $4.3 \mathrm{~mol} \%)$.

Previously Wong et al. (2017) investigated the acidic hydrolysis of $87 \mathrm{wt} \% \mathrm{GVL}$ at room temperature using high concentrations of $\mathrm{H}_{2} \mathrm{SO}_{4}(0.01-4.05 \mathrm{~mol} /$ $\mathrm{L})$ and $\mathrm{HCl}(0.02-2 \mathrm{~mol} / \mathrm{L})$, yielding in $<4 \mathrm{~mol} \%$ of 4-HVA (Wong et al. 2017). In our measurements, 4-HVA formation at room temperature was evident only at very low $\mathrm{pH}\left(\geq 0.5 \mathrm{wt} \% \mathrm{H}_{2} \mathrm{SO}_{4}, \mathrm{pH}_{\text {initial }}<1\right)$, which is consistent with the observation of Wong et al. (2017) (Fig. 5). Additionally, this study investigated the GVL ring-opening also at higher $\mathrm{pH}$ range $(\mathrm{pH}$ 2-6) at room temperature, concluding that with increasing $\mathrm{pH}$ near neutral, the 4-HVA formation could not be detected (Fig. 5). However, unlike the reported acid hydrolysis from Wong et al. (2017), the

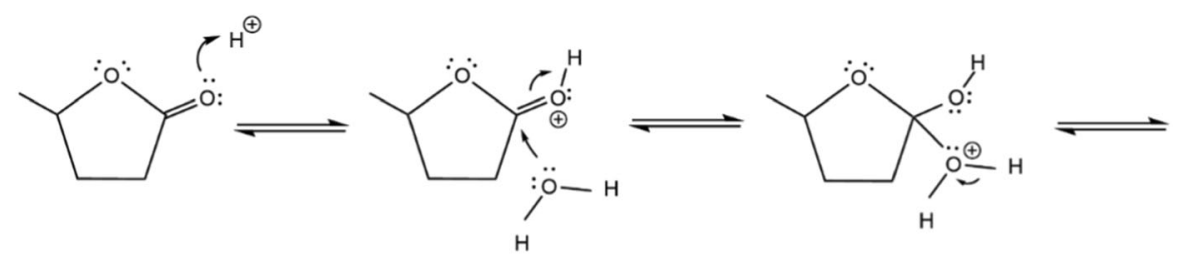

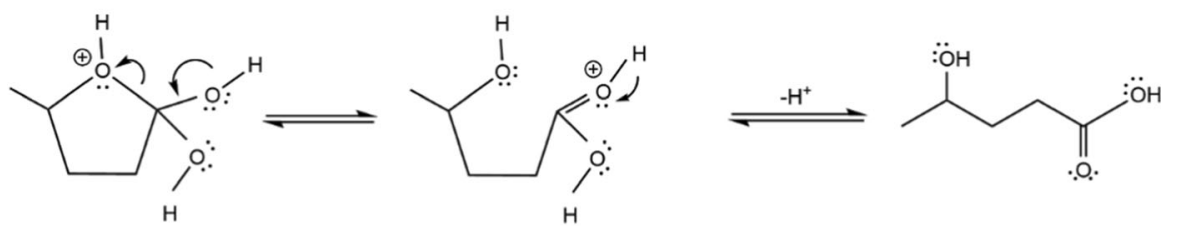

Fig. 3 Mechanism of hydrolysis of GVL in an acidic environment 


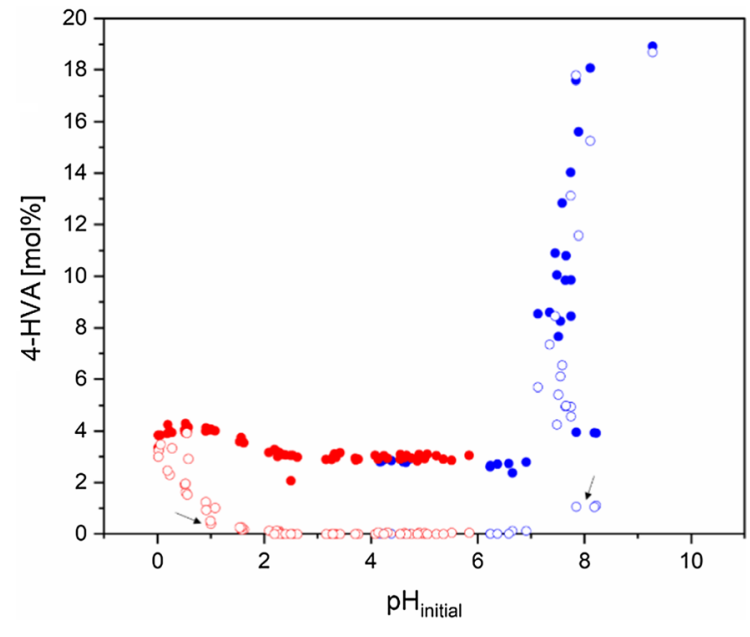

Fig. 5 Formation of 4-HVA/ 4-hydreoxyvalerate in a GVLwater solution at acidic $\left(\mathrm{H}_{2} \mathrm{SO}_{4}\right.$, red) and basic $(\mathrm{NaOH}$, blue $)$ conditions before thermal treatment (red circle, blue circle) and after thermal treatment (red filled circle, blue filled circle) $\left(150-180{ }^{\circ} \mathrm{C}\right)$. Arrows indicate the threshold of spontaneous ring opening in alkaline $(\geq 0.2 \mathrm{wt} \% \mathrm{NaOH})$ and acidic $(\geq 0.5$ wt $\% \mathrm{H}_{2} \mathrm{SO}_{4}$ ) environment

results of this study exhibited an opposite trend, meaning that higher acidity induced the formation of 4-HVA to larger extent. In Fig. 5 the threshold of the spontaneous GVL ring-opening as a function of $\mathrm{pH}$ of the solution before heating is presented. In other words, GVL remains stable at the $\mathrm{pH}$ range $2-7$ at ambient conditions. Moreover, it illustrates the increase of 4-HVA concentration after heating at the initial conditions. The shifts of the $\mathrm{pH}$ values (before and after) at specific treatment conditions as well as the corresponding 4-HVA concentrations are listed in Table S2.

To avoid the extensive number of measurements resulting from all possible combinations of reaction conditions (temperature, time, and concentration) for the individual samples, the conditions were chosen based on a fractional factorial design of high resolution. Choosing the model allowed the estimation of the main and first-order interaction effects of the variables on GVL hydrolysis. Further statistical evaluation of experimental data obtained from acidic hydrolysis revealed that the alteration of the time and temperature once the equilibrium is reached has no significant effect on GVL hydrolysis. Consequently, the acid concentration remained the main influence on hydrolysis.
Figure 6 graphically represents the margins in which the time and temperature affect the hydrolysis. Despite the gradual increase of reaction time or temperature, the 4-HVA remained relatively constant. The $\mathrm{H}_{2} \mathrm{SO}_{4}$ concentration ranged from 0.0 to $6.0 \mathrm{wt} \%$ $\left(\mathrm{pH}_{\text {initial }}=0-6\right)$ and it can be tracked from Fig. 6 and Table S2.

Besides, the hydrolysis of esters is favored in an alkaline environment as well. Thereby, the hydroxide ion gained from a strong base like $\mathrm{NaOH}$ acts as a nucleophile, which attacks the electropositive carbon of the ester unit. At these certain conditions, the reaction is irreversible and driven towards the formation of the salt. A carboxylate ion is formed and stabilized by a suitable positive counter ion (Fig. 7) (Clayden et al. 2012; Graham 2004). The presence of sodium 4-hydroxyvalerate after the reaction of GVL with aqueous $\mathrm{NaOH}$ was previously confirmed by Horváth et al. (2008).

The experiments in the alkaline environment were conducted at constant time (30 $\mathrm{min}$ ) and temperature $\left(180^{\circ} \mathrm{C}\right)$ with the variation of the $\mathrm{NaOH}$ dosage. Higher concentrations of $\mathrm{NaOH}\left(\geq 0.2 \mathrm{wt} \%, \mathrm{pH}_{\text {initial- }}\right.$ $>8$ ) facilitated the GVL ring-opening ( $\geq 1 \mathrm{~mol} \%)$ already before heating accompanied by a gradual drop of the $\mathrm{pH}$ (Fig. 5). After the treatment, stabilization of $\mathrm{pH}$ was reached, and no further decrease in the $\mathrm{pH}$ value was recognized. The addition of less than 0.2 wt $\%$ of $\mathrm{NaOH}$ resulted in the formation of $<4 \mathrm{~mol} \%$

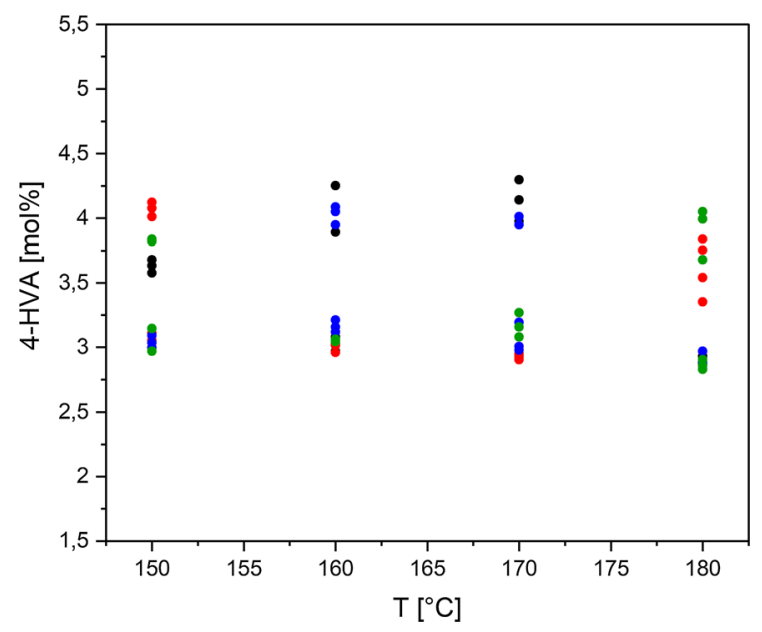

Fig. 6 Formation of 4-HVA as a function of temperature in a GVL-water solution in the presence of $\mathrm{H}_{2} \mathrm{SO}_{4}(0.0-6.0 \mathrm{wt} \%$, $\mathrm{pH}=0-6$ ): black filled circle $30 \mathrm{~min}$, red filled circle $60 \mathrm{~min}$, blue filled circle $120 \mathrm{~min}$, green filled circle $180 \mathrm{~min}$ 


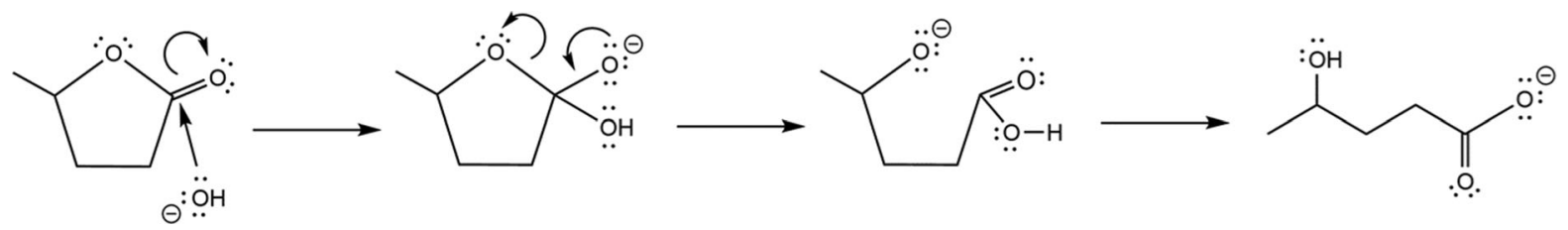

Fig. 7 Mechanism of hydrolysis of GVL in an alkaline environment

of sodium 4-hydroxyvalerate (Fig. 4b), while an amount of $21 \mathrm{~mol} \%$ 4-HVA was observed as the largest amount in a $7 \mathrm{wt} \% \mathrm{NaOH}$ solution. This result confirmed the significant influence of the alkaline environment on the stability of GVL. Higher concentrations of $\mathrm{NaOH}$ significantly help to shift the reaction toward the formation of sodium 4-hydroxyvalerate. The linear increase of 4-hydroxyvalerate implied that the GVL hydrolysis could extend beyond $21 \mathrm{~mol} \%$ by a simultaneous elevation of $\mathrm{NaOH}(>7$ $\mathrm{wt} \%)$. However, such high concentrations of alkali are neither favorable nor practical for pulping purposes, and for technical reasons, no further investigations have been performed.

Wong et al. (2017) also investigated the stability of GVL under aqueous alkaline conditions in the presence of a $25 \mathrm{~mol} \% \mathrm{NH}_{4} \mathrm{OH}$ solution at room temperature. Fifteen hours after the reaction, an extent of GVL hydrolysis of $30 \mathrm{~mol} \%$ was reported (Wong et al. 2017). The amount of hydrolysis in alkaline environment was observed immediately and confirmed by our measurements.

Moreover, a bi-phasic system was observed after the mixing of $50 \mathrm{wt} \%$ GVL solution with $\geq 1.3 \mathrm{wt} \%$ $\mathrm{NaOH}$. Both phases were analyzed. The upper organic phase released an enrichment of GVL and the lower aqueous layer of the 4-hydroxyvalerate. This phenomenon is commonly known as a salting-out effect. A large amount of salt decreases the solubility of GVL and causes a liquid layer formation.

\section{Equilibrium model for 4-HVA formation}

An addition of $\mathrm{H}_{2} \mathrm{SO}_{4}$ to an aqueous solution of GVL catalyzes the hydrolysis reaction.

In general, the dissociation of sulfuric acid follows a two steps deprotonation, which yields first in the production of hydrogen sulfate $\left(\mathrm{HSO}_{4}{ }^{-}\right)$and finally in the formation of the dianion sulfate $\left(\mathrm{SO}_{4}{ }^{2-}\right)$. As $\mathrm{H}_{2} \mathrm{SO}_{4}$ is a strong acid, the first dissociation reaction will be almost complete. As for the second dissociation reaction, it can be described by the equilibrium Eq. (1), where $\mathrm{K}$ is an equilibrium constant:

$\left[\mathrm{H}_{3} \mathrm{O}^{+}\right]\left[\mathrm{SO}_{4}^{2-}\right]=\mathrm{K}\left[\mathrm{HSO}_{4}^{-}\right]\left[\mathrm{H}_{2} \mathrm{O}\right]$

Furthermore, omitting the intermediate steps in the ring-opening mechanism leads to the equilibrium Eq. (2) with the equilibrium constant $\mathrm{K}_{\text {ring: }}$ :

$[4 \mathrm{HVA}]=\mathrm{K}_{\text {ring }}[\mathrm{GVL}]\left[\mathrm{H}_{2} \mathrm{O}\right]$

As a result, the equilibrium Eqs. (1) and (2) contain six different molar concentrations $\left(\left[\mathrm{H}_{3} \mathrm{O}^{+}\right],\left[\mathrm{SO}_{4}{ }^{2-}\right]\right.$, $\left[\mathrm{HSO}_{4}{ }^{-}\right],\left[\mathrm{H}_{2} \mathrm{O}\right],[\mathrm{GVL}]$ and [4-HVA]), which are obtained from the considerations of molar balance and electroneutrality. $\mathrm{H}_{2} \mathrm{O}$ participates in one reaction forming $\mathrm{H}_{3} \mathrm{O}^{+}$and another forming 4-HVA, both at mole-to-mole ratio 1:1. Consequently, the denotation $\mathrm{c}_{1}$ (Eq. 3) concludes that the molar amounts of these constituents must be the same as the initial molar amount of $\mathrm{H}_{2} \mathrm{O}$ and $\mathrm{H}_{3} \mathrm{O}^{+}$(after the first dissociation of $\mathrm{H}_{2} \mathrm{SO}_{4}$ ). Furthermore, the initial concentration of $\left[\mathrm{HSO}_{4}{ }^{-}\right]\left(\mathrm{c}_{2}\right)$ and GVL $\left(\mathrm{c}_{3}\right)$ are achieved by Eqs. 4 and 5.

$$
\begin{aligned}
& {\left[\mathrm{H}_{2} \mathrm{O}\right]+\left[\mathrm{H}_{3} \mathrm{O}^{+}\right]+[4 \mathrm{HVA}]=\mathrm{c}_{1}} \\
& {\left[\mathrm{HSO}_{4}^{-}\right]+\left[\mathrm{SO}_{4}^{2-}\right]=\mathrm{c}_{2}} \\
& {[\mathrm{GVL}]+[4 \mathrm{HVA}]=\mathrm{c}_{3}}
\end{aligned}
$$

At the same time, the equation of electroneutrality is defined as:

$$
\left[\mathrm{H}_{3} \mathrm{O}^{+}\right]=\left[\mathrm{HSO}_{4}^{-}\right]+2\left[\mathrm{SO}_{4}^{2-}\right]
$$

Now, it is possible to solve the system of Eqs. (1)(6) and obtain an estimate e.g., for the concentration of 4-HVA as a function of initial $\mathrm{H}_{2} \mathrm{SO}_{4}$ concentration and ring-opening Equilibrium constant $\mathrm{K}_{\text {ring }}$. The fact that the equation system contains products of different concentrations leads to a nonlinear behavior and thus to several solutions one of which being chemically 
meaningful. However, there is no way the two equilibrium Eqs. (1) and (2) could account for the observation in the experimental data of the 4-HVA concentration at equilibrium increasing with lower $\mathrm{pH}$. Therefore, we just fit the model to the data points with higher $\mathrm{pH}$ values to obtain the estimate $\mathrm{K}_{\text {ring- }}$ $=5.7 \times 10^{-3}$ for the ring-opening equilibrium constant and extrapolate the model to the lower $\mathrm{pH}$ values to compare its predictions to those observed as in Fig. 8.

Wong et al. (2017) proposed the model for the acidic $\mathrm{pH}$ range $0-2$ (Wong et al. 2017). The suggested model displays a decrease in 4-HVA concentration at low $\mathrm{pH}$ values what could be also partly observed in our data. However, the model presented by Wong et al. (2017) does not describe the $\mathrm{pH}$ range below 1 (Fig. 8). The peak in the data at a $\mathrm{pH}$ value just below 1 would seem to require an additional element in the model where the presence of sulfuric acid promotes the formation of 4-HVA even at equilibrium. The difference between model and experimental data implies that there could be present another reaction. To find a valid proposal for this equilibrium reaction, further measurement is needed.

In the alkaline environment, the $\mathrm{NaOH}$ reacts with the GVL forming a salt. Hence, the $\mathrm{pH}$ level increases only moderately despite the addition of sodium hydroxide. It is however not obvious what is the mechanism behind the relative stability of GVL under alkaline conditions that according to experimental data prevents the complete conversion independent of

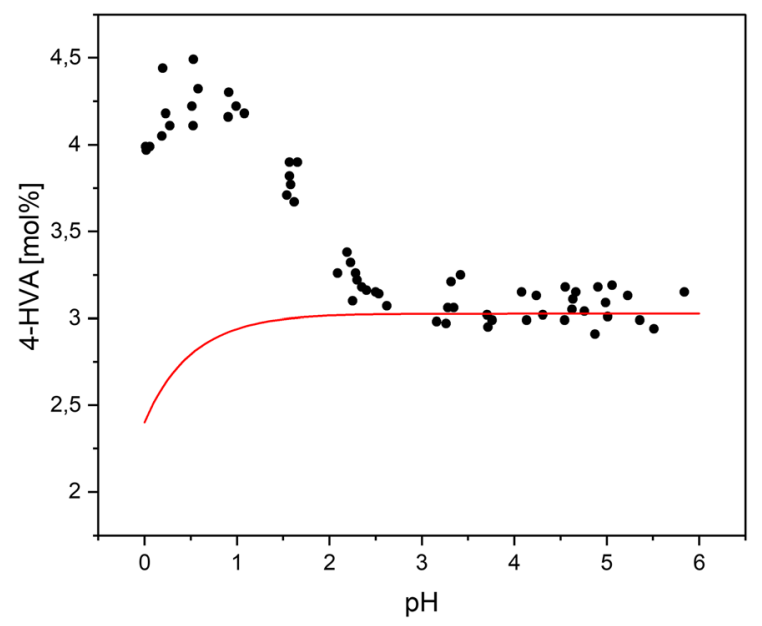

Fig. 8 Equilibrium model compared to acidic 4-HVA data: black filled circle experimental data, red line model the treatment time. If the alkaline hydrolysis is an equilibrium reaction the equilibrium constant $\mathrm{K}_{\mathrm{AH}}$ is calculated by Eq. (7)

$$
\left[4 \mathrm{HVA}^{-}\right]=\mathrm{K}_{\mathrm{AH}}[\mathrm{GVL}]\left[\mathrm{OH}^{-}\right]
$$

Figure 9 shows a fitted kinetic model assuming an equilibrium reaction between GVL and the 4-HVA salt in addition to the uncatalyzed equilibrium reaction between GVL and 4-HVA, also present during acidic conditions. The alkaline model fit renders the value 0.13 to the equilibrium constant for the reaction of GVL and the 4-HVA salt. The summary of the equilibrium constants can be found in Table S5.

GVL hydrolysis and formation of 4-HVA during Betula pendula fractionation

The organosolv fractionation excels in its potency to effectively delignify the biomass even without the addition of sulfur-containing chemicals what makes it significantly ecologically approachable. It can run either as auto-catalyzed, when the hydrolysis is enhanced only by acetic acid released from hemicelluloses, with the help of mineral acid, or some of the processes were intended as alkali-organosolv (Azadi et al. 2013). The GVL process was widely studied as an auto-catalyzed or acid-catalyzed process. Consequently, in this study, the stability of GVL was examined under real pulping conditions in acidic and alkaline conditions.

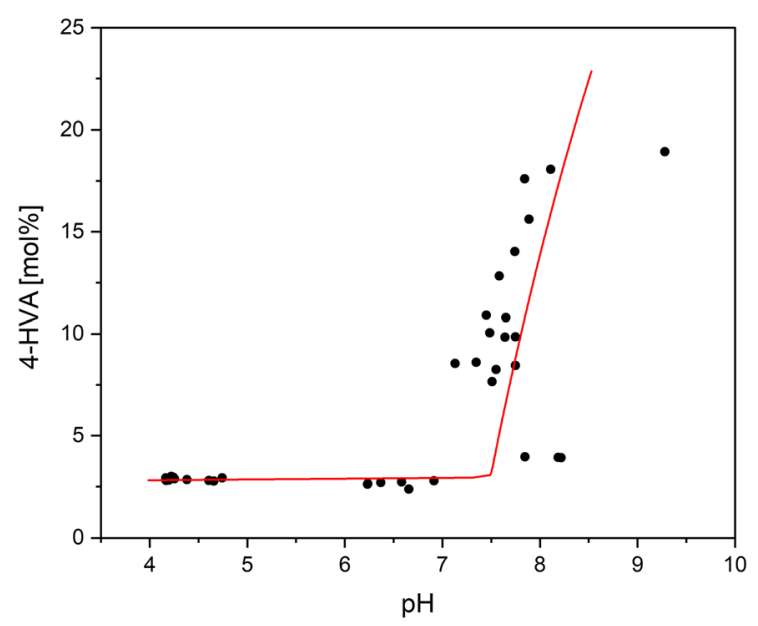

Fig. 9 Equilibrium model fitted to alkaline 4-HVA data: black filled circle experimental data, red line model 
Betula pendula sawdust was fractionated in $50 \mathrm{wt} \%$ GVL with and without the addition of $\mathrm{H}_{2} \mathrm{SO}_{4}$ or $\mathrm{NaOH}$ at $180{ }^{\circ} \mathrm{C}$ using a reaction time of $120 \mathrm{~min}$. The NMR analysis revealed that the spent liquor contained 4-HVA and a small amount of acetic acid (Figure S15). The presence of levulinic (LA) acid and formic acid (FA) was not detected by NMR. In a highly acidic environment ( $20 \mathrm{~kg} \mathrm{H}_{2} \mathrm{SO}_{4} / \mathrm{t}$ wood), the formation of 4-HVA was $5.6 \mathrm{~mol} \%$ and in an extremely alkaline (192 $\mathrm{kg} \mathrm{NaOH} / \mathrm{t}$ wood), the 4-HVA did not exceed $6.0 \mathrm{~mol} \%$ (Fig. 10, Table 1). In addition, Fig. 10 illustrates the average formation of 4-HVA without wood for comparison.

The carboxylic acids derived from the fractionation of wood, may partly neutralize $\mathrm{NaOH}$ and hence, lower the concentration of 4-HVA. On the contrary, in comparison with the results achieved in the absence of wood, the 4-HVA concentration slightly increased in the fractionation with the highest acid charge $(17 \mathrm{~kg}$ $\mathrm{H}_{2} \mathrm{SO}_{4} / \mathrm{t}_{\mathrm{odw}}$ ). The slight increase of 4-HVA during the fractionation can be caused also by the substantial degradation of cellulose under highly acidic conditions (Table S6), which could contribute to the formation of LA and further to 4-HVA. The fractionation of carbohydrates is followed by a series of chemical reactions including acidic hydrolysis of

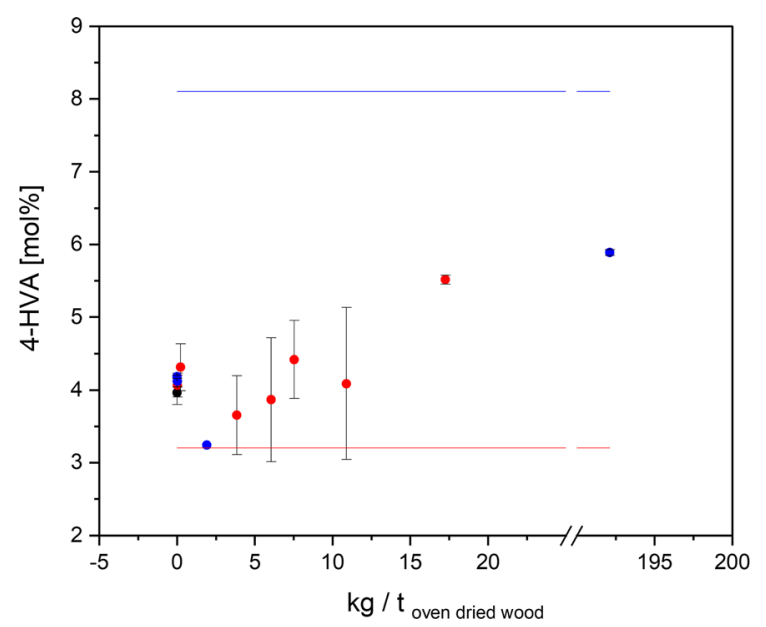

Fig. 10 The concentration of 4-HVA in spent liquor after fractionation of Betula pendula in an equiponderant GVL-water solution $50 \% \mathrm{GVL}$ at $180{ }^{\circ} \mathrm{C}$ and $120 \mathrm{~min}$ : black filled circle without catalyst, red filled circle with $\mathrm{H}_{2} \mathrm{SO}_{4}$, and blue filled circle with $\mathrm{NaOH}$, red line without wood in acidic environment, blue without wood in alkaline environment. The error bars represent the standard deviation of the individual measurements with the same reaction conditions glycosidic bonds. As a result, acid-catalyzed reactions lead to the degradation of hexoses forming LA and FA at higher temperatures (Sjöström 1993). Further reduction of LA by hydrogenation yields to 4-HVA which lactonizes to GVL (Deng et al. 2010; Yan et al. 2009). However, to prove this hypothesis, more investigations are needed.

Alonso et al. (2017) also investigated the stability of GVL in the presence of biomass components, but only using acetic acid as a model compound at a concentration of $5 \mathrm{wt} . \%$. After $12 \mathrm{~h}$, at $130{ }^{\circ} \mathrm{C}$ and in the presence of $0.1 \mathrm{M} \mathrm{H}_{2} \mathrm{SO}_{4}$, the formation of 4-HVA together with levulinic acid did not exceed $0.4 \mathrm{~mol} \%$. The discrepancy in 4-HVA concentration between Alonso et al. (2017) and this study could be due to the lower water content in the GVL/water mixture (70/30 and 50/50, respectively).

\section{Conclusion}

GVL hydrolysis to 4-HVA under the specific conditions of a biomass fractionation process was investigated. The hydrolysis occurs at higher temperatures $\left(>150{ }^{\circ} \mathrm{C}\right)$ and in acid and alkaline catalyzed environments. 4-HVA reaches a stable value ( $>4 \mathrm{~mol} \%$ ), and only under extreme alkaline conditions, GVL can hydrolyze up to $20 \mathrm{~mol} \%$. The same trend of hydrolysis was followed during the biomass fractionation. The $\mathrm{pH}$ window $(\mathrm{pH}=2-7)$ demonstrates GVL stability at ambient conditions independent of the concentration of the catalyst. The next step is to investigate the extent to which a $3-6 \mathrm{~mol} \%$ 4HVA content in the spent liquor affects the recovery of GVL by liquid $\mathrm{CO}_{2}$ extraction and, in addition, whether 4-HVA is involved in loss reactions with wood components.

Authors' contributions M Granatier: Investigation, WritingOriginal Draft, Visualization; I Schlapp-Hackl: Methodology, Writing-Review \& Editing; Q. L. Huy: Writing-Review \& Editing, Project administration; K. Nieminen: Formal analysis; L. Pitkänen: Formal analysis; H. Sixta: Conceptualization, Supervision, Writing-Review \& Editing, Funding Acquisition.

Funding Open access funding provided by Aalto University. This work was funded by the Academy of Finland's Flagship Programme under Projects No. 318890 and 318891 (Competence Center for Materials Bioeconomy, FinnCERES). 


\section{Declarations}

Conflict of interest The authors declare that they have no known competing financial interests or personal relationships that could have appeared to influence the work reported in this paper.

Consent to participate The work in the manuscript is original and conducted by all the authors.

Consent to publication All authors agree on submitting the manuscript for publication to Cellulose.

Open Access This article is licensed under a Creative Commons Attribution 4.0 International License, which permits use, sharing, adaptation, distribution and reproduction in any medium or format, as long as you give appropriate credit to the original author(s) and the source, provide a link to the Creative Commons licence, and indicate if changes were made. The images or other third party material in this article are included in the article's Creative Commons licence, unless indicated otherwise in a credit line to the material. If material is not included in the article's Creative Commons licence and your intended use is not permitted by statutory regulation or exceeds the permitted use, you will need to obtain permission directly from the copyright holder. To view a copy of this licence, visit http://creativecommons.org/licenses/by/4.0/.

\section{References}

Alonso DM, Hakim SH, Zhou S, Won W, Hosseinaei O, Tao J, Garcia-Negron V, Motagamwala AH, Mellmer MA, Huang K, Houtman CJ, Labbé N, Harper DP, Maravelias CT, Runge T, Dumesic JA (2017) Increasing the revenue from lignocellulosic biomass: maximizing feedstock utilization. Sci Adv 3:1-7. https://doi.org/10.1126/sciadv. 1603301

Azadi P, Inderwildi OR, Farnood R, King DA (2013) Liquid fuels, hydrogen and chemicals from lignin: a critical review. Renew Sustain Energy Rev. https://doi.org/10. 1016/j.rser.2012.12.022

Chen C, Duan C, Li J, Liu Y, Ma X, Zheng L, Stavik J, Ni Y (2016) Cellulose (dissolving pulp) manufacturing processes and properties: a mini-review. BioResources 11:5553-5564. https://doi.org/10.15376/biores.11.2.Chen

Clayden J, Greeves N, Warren S (2012) Chapter 10 Nucleophilic substitution at the carbonyl group. In: Organic chemistry, 2nd edn, Oxford University Press, Oxford, United Kingdom, pp 205-212.ISBN 10:0199270295

Deng L, Zhao Y, Li J, Fu Y, Liao B, Guo QX (2010) Conversion of levulinic acid and formic acid into $\gamma$-valerolactone over heterogeneous catalysts. Chemsuschem 3:1172-1175. https://doi.org/10.1002/cssc.201000163

Engelhardt A (2020) The Fiber Year 2020 World Survey on Textiles \& Nonwovens. https://www.thefiberyear.com/ fileadmin/pdf/2020/TFY2020_TOC.pdf. Accessed 16 July 2021
Fang W, Sixta H (2014) Advanced biorefinery based on the fractionation of biomass in $\gamma$-valerolactone and water. Chemsuschem 8:73-76. https://doi.org/10.1002/cssc. 201402821

Gellerstedt G (2009) Chapter 5 Chemistry of chemical pulping. In: Monica Ek, Gellerstedt G, Henriksson G (eds) Volume 2 Pulping Chemistry and Technology, De Gruyter, pp 91-120, ISBN: 9783110213416. https://doi.org/10. 1515/9783110213423

Gómez-Bombarelli R, Calle E, Casado J (2013a) Mechanisms of lactone hydrolysis in acidic conditions. J Org Chem 78:6880-6889. https://doi.org/10.1021/jo4002596

Gómez-Bombarelli R, Calle E, Casado J (2013b) Mechanisms of lactone hydrolysis in neutral and alkaline conditions. J Org Chem 78:6868-6879. https://doi.org/10.1021/ jo400258w

Graham P (2004) Chapter K6 Carboxylic acids and carboxylic acid derivatives. In: Patrick G (ed) BIOS instant notes in organic chemistry, 2nd edn. Taylor \& Francis Ltd, London, United Kingdom, pp 221-230. ISBN 101859962645

Henriksson G, Lennholm H (2009) Chapter 4 Cellulose and carbohydrate chemistry. In: Monica Ek, Gellerstedt G, Henriksson G (eds) Volume 1 Wood chemistry and wood biotechnology, pp 71-99, De Gruyter. ISBN: 9783110213393. https://doi.org/10.1515/9783110213409

Horváth IT, Mehdi H, Fábos V, Boda L, Mika LT (2008) $\gamma$ Valerolactone-a sustainable liquid for energy and carbonbased chemicals. Green Chem 10:238-242. https://doi.org/ $10.1039 / \mathrm{b} 712863 \mathrm{k}$

Janson J (1970) Calculation of the polysaccharide composition of wood and pulp. Pap Ja Puu 5:323

Kleinert TN, Tayenthal K (1931) Über neuere Versuche zur Trennung von Cellulose und Incrusten Verschiedener Hölzer. Angew Chem 44:788-791

Lê HQ, Dimic-Misic K, Johansson LS, Maloney T, Sixta H (2018a) Effect of lignin on the morphology and rheological properties of nanofibrillated cellulose produced from $\gamma$ valerolactone/water fractionation process. Cellulose 25:179-194. https://doi.org/10.1007/s10570-017-1602-5

Lê HQ, Ma Y, Borrega M, Sixta H (2016a) Wood biorefinery based on $\gamma$-valerolactone/water fractionation. Green Chem 18:5466-5476. https://doi.org/10.1039/C6GC01692H

Lê HQ, Pokki JP, Borrega M, Uusi-Kyyny P, Alopaeus V, Sixta $\mathrm{H}$ (2018b) Chemical recovery of $\hat{\mathrm{I}}$-Valerolactone/water biorefinery. Ind Eng Chem Res 57:15147-15158. https:// doi.org/10.1021/acs.iecr.8b03723

Lê HQ, Zaitseva A, Pokki JP, Ståhl M, Alopaeus V, Sixta H (2016b) Solubility of organosolv lignin in $\gamma$-valerolactone/ water binary mixtures. Chemsuschem 9:2939-2947. https://doi.org/10.1002/cssc.201600655

Li M, Li W, Liu Q, Jameel H, Chang H, An S, Ma L (2016) A Two-step conversion of corn stover into furfural and levulinic acid in a water/gamma-valerolactone system. BioResources 11:8239-8256. https://doi.org/10.15376/ biores.11.4.8239-8256

Luterbacher JS, Rand JM, Alonso DM, Han J, Youngquist JT, Maravelias CT, Pfleger BF, Dumesic JA (2014) Nonenzymatic sugar production from biomass using biomassderived $\gamma$-valerolactone. Science 343:277-280. https://doi. org/10.1126/science. 1246748 
Mendes CVT, Carvalho MGVS, Baptista CMSG, Rocha JMS, Soares BIG, Sousa GDA (2009) Valorisation of hardwood hemicelluloses in the kraft pulping process by using an integrated biorefinery concept. Food Bioprod Process 87:197-207. https://doi.org/10.1016/j.fbp.2009.06.004

Qing Q, Gao X, Wang P, Guo Q, Xu Z, Wang L (2018) Dilute acid catalyzed fractionation and sugar production from bamboo shoot shell in $\gamma$-valerolactone/water medium. RSC Adv 8:17527-17534. https://doi.org/10.1039/c8ra02891e

Schild G, Sixta H, Testova L (2010) Multifunctional alkaline pulping, delignification and hemicellulose extraction. Cellul Chem Technol 44:35-45

Shuai L, Questell-Santiago YM, Luterbacher JS (2016) A mild biomass pretreatment using $\gamma$-valerolactone for concentrated sugar production. Green Chem. https://doi.org/10. $1039 / \mathrm{c} 5 \mathrm{gc} 02489 \mathrm{~g}$

Sixta H (2006) Part I 1 Chemical pulping, In: Sixta H (ed) Handbook of pulp, Wiley, pp 2-19. ISBN: 9783527309993. https://doi.org/10.1351/ pac197645030181

Sixta H, Iakovlev M, Testova L, Roselli A, Hummel M, Borrega M, Van Heiningen A, Froschauer C, Schottenberger H (2013) Novel concepts of dissolving pulp production. Cellulose 20:1547-1561. https://doi.org/10.1007/s10570013-9943-1
Sjöström E (1993) Wood chemistry fundamentals and applications, 2nd edn. Academic Pressn Inc., San Diego

Statista (2021) Production of chemical pulp worldwide 2010-2018 [WWW Document]. https://www.statista.com/ statistics/1178289/production-of-chemical-pulpworldwide/. Accessed 16 July 2021

van Heiningen A, Sharazi AM, Tunc MS (2018) Reactions of ethanol with xylan and lignin in acid catalyzed organosolv pulping: implications for ethanol recovery and process selection. In: EWLP conference in Aveiro, Portugal

Wong CYY, Choi AWT, Lui MY, Fridrich B, Horváth AK, Mika LT, Horváth IT (2017) Stability of gamma-valerolactone under neutral, acidic, and basic conditions. Struct Chem 28:423-429. https://doi.org/10.1007/s11224-0160887-6

Yan ZP, Lin L, Liu S (2009) Synthesis of $\gamma$-valerolactone by hydrogenation of biomass-derived Levulinic acid over Ru/ C catalyst. Energy Fuels 23:3853-3858. https://doi.org/10. 1021/ef900259h

Publisher's Note Springer Nature remains neutral with regard to jurisdictional claims in published maps and institutional affiliations. 